1984 jun • volume $58 \bullet$ no. $2 \bullet$ pages $79-174$ issn $0022149 x$

Journal of

Teiminthology

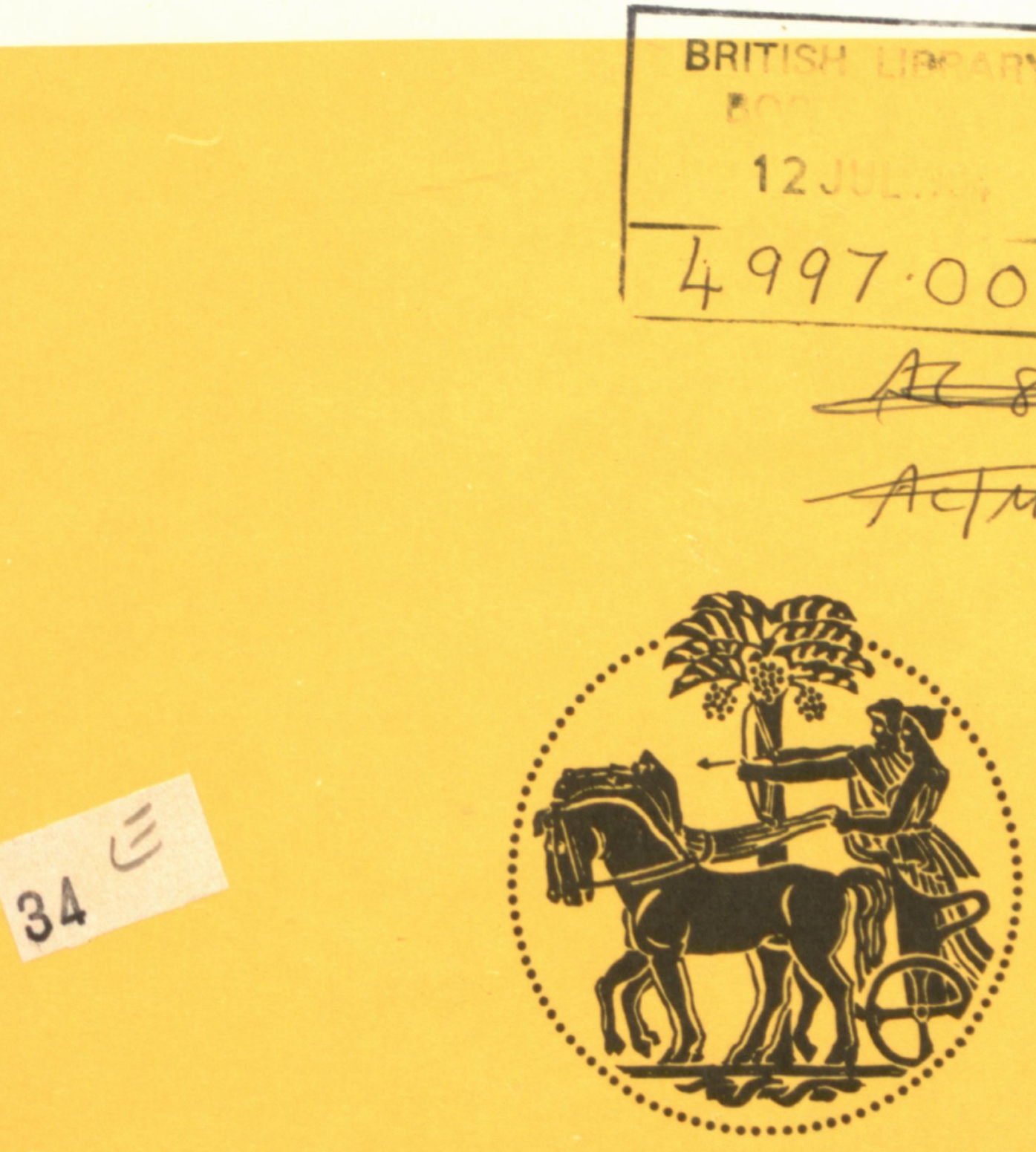

London Sehool of forygiene and Tropical Medicine 


\section{JOURNAL OF HELMINTHOLOGY}

(Founded by R. T. Leiper in 1923 and edited from 1946-72 by J. J. C. Buckley and from 1972-80 by R. Muller)

EDITOR: Dr. Sheila Willmott

London School of Hygiene \& Tropical Medicine,

Winches Farm Field Station,

395 Hatfield Road,

St Albans, Herts AL4 OXQ, England.

Subscriptions and advertisement enquiries should be sent to:

Bureau of Hygiene \& Tropical Diseases,

Keppel Street,

London WC1E 7HT, England.

Published in 4 parts per year

Subscription from $1984 £ 31.50$ per annum

(U.S.\$78·50)

Back volumes should be ordered from Wm. Dawson \& Sons Ltd., (Back Issues Dept.), Cannon House, Folkestone, Kent CT19 5EE, England. Prices on application. 